\title{
Xylem Functioning and Water Relations of the Elastic Living Tissue of the Bark: New Insights about Their Coordination
}

\author{
A. Díaz-Espejo ${ }^{1}$, E. Nicolás ${ }^{3}$, P. Nortes ${ }^{3}$, C.M. Rodriguez-Dominguez ${ }^{1,2}$, M.V. Cuevas ${ }^{1}$, \\ A. Perez-Martin ${ }^{1}$ and J.M. Torres-Ruiz ${ }^{1}$ \\ ${ }^{1}$ Irrigation and Crop Ecophysiology Group, Instituto de Recursos Naturales y \\ Agrobiología, IRNAS-CSIC, Apartado 1052, 41080, Sevilla, Spain \\ 2 Dpto. Biología Vegetal y Ecología, Universidad de Sevilla, Avda. Reina Mercedes 6, \\ 41012-Sevilla, Spain \\ ${ }^{3}$ Dpto. Riego, Centro de Edafología y Biología Aplicada del Segura (CSIC), Apartado \\ 164, 30100 Espinardo (Murcia), Spain
}

Keywords: stem water potential, dendrometers, vulnerability curve, osmotic pressure, turgor pressure, water use, water stress

\begin{abstract}
The interesting species-specific relationship between maximum daily shrinkage (MDS) and stem water potential $\left(\Psi_{\text {stem }}\right)$ was investigated in order to understand the mechanisms involved. Vulnerability curves of Vitis, Citrus, Olea and Prunus were analysed and the air entry $\Psi_{\text {stem }}$ in the xylem $\left(P_{\mathrm{e}}\right)$ was calculated. The water relations parameters of the living tissue of the bark were also studied by building P-V curves. A strong linear correlation was obtained between the $\Psi_{\text {stem }}$ at which MDS occurs ( $\Psi_{\text {MDS }}$ ) and $\boldsymbol{P}_{\mathrm{e}}$ in the studied species. Furthermore, P-V curves showed that, the species with the highest resistance to cavitation, i.e., Prunus, had the lowest osmotic pressure and the largest bulk elastic modulus. The conclusions of this study reinforce the idea of a tight correlation among plant capacitance, transpiration and maintenance of water status of the plant. These results illustrate the importance of studying the integration of long-distance transport systems in plants.
\end{abstract}

\section{INTRODUCTION}

Monitoring of trunk diameter variations (TDV) on the bark of woody plants is becoming a useful tool for managing irrigation in commercial orchards. In addition to being a valuable feature for agronomists, these sensors supply important information about the physiological mechanisms that allow the plant to transpire under a wide range of environmental conditions. Currently, it is not possible to mechanistically explain the daily and seasonal dynamics of transpiration without considering the role played by water storage in trunks, branches and even leaves (Steppe et al., 2006). Trunk diameter fluctuations have been reported to reflect the addition of four components: irreversible radial growth, reversible living-cell dehydration/rehydration, thermal expansion and contraction, and expansion of dead conducting elements due to the increase and relaxation of internal tensions. Therefore, the interaction between both the living parenchyma in the cortex and the xylem is important to understand the dynamics of TDV and its consequences on the water relations observed in the plant. Maximum daily shrinkage (MDS) is one of the most used indicators of water stress in fruit trees (Fernandez and Cuevas, 2010). When plotted against stem water potential ( $\left.\Psi_{\text {stem }}\right)$ MDS shows a parabolic response, i.e., as $\Psi_{\text {stem }}$ decreases MDS increases up to a maximum value after which MDS decreases following further decreases in $\Psi_{\text {stem. }}$. Furthermore, the $\Psi_{\text {stem }}$ value at maximum MDS has been reported to be species-specific (Ortuño et al., 2010). The aim of this work was to investigate potential relationships between the pattern of MDS described above and the vulnerability to embolism of the xylem of several fruit tree species of high agronomical interest. 
features in the response of MDS and percentage of loss of conductivity of the xylem

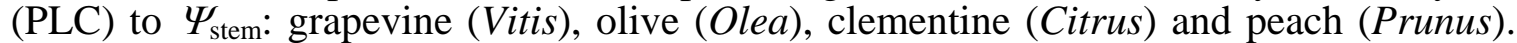
For most of them we were able to find information about the relationship of MDS and PLC with $\Psi_{\text {stem. }}$. In the cases where this was not possible, specific measurements were carried out as described below.

\section{MDS and $\Psi_{\text {stem }}$}

MDS values and their relationship with $\Psi_{\text {stem }}$ were obtained from Ortuño et al. (2010) for Vitis, Olea and Citrus. In the case of Prunus, four linear variable displacement transducers (LVDTs) were installed in 8-year-old almond trees (Prunus dulcis (Mill.) D.A. Webb 'Marta' on Mayor rootstock) planted in a 1 ha experimental orchard located in Murcia (Spain). Three irrigation treatments were assessed: (i) full irrigation (FI), irrigated to satisfy maximum crop water requirements $\left(\mathrm{ET}_{\mathrm{c}}\right)$ throughout the whole growing season; (ii) regulated deficit irrigation (RDI), irrigated at $20 \% \mathrm{ET}_{\mathrm{c}}$ during kernelfilling (stage IV, from end of May to end of August) and at $100 \% \mathrm{ET}_{\mathrm{c}}$ throughout the remainder of the growth cycle; (iii) not irrigation (NI). MDS was recorded daily automatically; meanwhile $\Psi_{\text {stem }}$ was measured with a pressure chamber twice per week.

\section{PLC and $\Psi_{\text {stem }}$}

Data for Vitis was obtained from Choat et al. (2010), Poggi et al. (2007) for Citrus, Diaz-Espejo et al. (2012) for Olea, and Cochard et al. (2010) for Prunus. Information was extracted from figures in those works and vulnerability curves were then generated by plotting PLCs against their corresponding $\Psi_{\text {stem }}$ values. Following Meinzer et al. (2009) the air entry pressure $\left(P_{\mathrm{e}}\right)$ can be estimated from the x-intercept of a tangent drawn through the midpoint of a sigmoid function fitted to the vulnerability curve data. This parameter $P_{\mathrm{e}}$ can be defined as the threshold at which loss of conductivity begins to increase rapidly.

\section{P-V Curves of Bark Tissue}

Bark samples were collected from six trees per species at $1.5 \mathrm{~m}$ height $(0.6 \mathrm{~m}$ in the case of Vitis). We used a 5-mm-diameter increment borer to take cylinders of outer parenchyma (living parenchymatous cells, cambium and phloem) down to sapwood. Samples were immediately sealed in glass vials in the field and transported to the laboratory where they were allowed to rehydrate. The water potential isotherms were determined with a thermocouple psychrometer with six standard C-52 sample chambers (Wescor Inc., Logan, UT, USA) connected to a datalogger (PSYPRO, Wescor Inc.).

\section{RESULTS AND DISCUSSION}

Figure 1 shows the response of MDS to $\Psi_{\text {stem }}$ in four species of high agronomical impact with contrasting characteristics. In all of them MDS increases with $\Psi_{\text {stem }}$ up to a specific $\Psi_{\text {stem }}$ value at which MDS is maximum and from which MDS starts declining. Vitis and Prunus presented the highest and lowest $\Psi_{\text {stem }}$ at maximum MDS ( $\Psi_{\text {MDS }}$ ), respectively. As an example, the calculation of $P_{\mathrm{e}}$ in Olea is plotted in Figure 2. While $P_{50}$ is estimated as ca. $-4.0 \mathrm{MPa}, P_{\mathrm{e}}$ is achieved just at $-1.55 \mathrm{MPa}$. $P_{\mathrm{e}}$ for Vitis, Citrus and Prunus were $-1.05,-1.20$ and $-2.10 \mathrm{MPa}$, respectively. These values indicate a different vulnerability to cavitation for each species, Vitis being the most vulnerable and Prunus the most resistant. When $P_{\mathrm{e}}$ was plotted against $\Psi_{\mathrm{MDs}}$ a linear correlation was found, very close to the line 1:1 (Fig. 3). This suggests a tight coordination between both aspects of water transport in plants. $P_{\mathrm{e}}$ is related to the capacity of water transport by the xylem, and any further decrease in $\Psi_{\text {stem }}$ below $P_{\mathrm{e}}$ would induce major losses in the hydraulic conductivity of the xylem. On the other hand, MDS is related to the capacitance of the plant (Steppe et al., 2006), and therefore plays an important role in slowing down changes in xylem pressure following transpiration-induced changes in xylem water flux (Meinzer et al., 2009). The occurrence of the largest MDS at a given $\Psi_{\text {stem }}$ means that, at that $\Psi_{\text {stem }}$, the capacity of water transfer from the elastic living tissue of the bark to the xylem 
becomes maximum. If $\Psi_{\text {stem }}$ keeps on declining, there is a concomitant decrease in both hydraulic conductivity and the capacitance of surrounding living tissue to supply water stored. From this point of view, it is not surprising that both parameters appear to be so well coordinated. Another key "actor" driving transpiration, the stomatal conductance, is also very much determined by the values of $\Psi_{\text {stem }}$ found in Figure 3. Again in all these species (Vitis: Schultz, 2003; Olea: Fernandez et al., 1997; Citrus: Garcia-Tejero et al., 2010; Prunus: Egea et al., 2011) there is a close relationship between $P_{\mathrm{e}}$ and the minimum value of $\Psi_{\text {stem }}$ (as defined by Meinzer et al., 2009) that is targeted by a strong and regulated stomatal closure.

How is this coordination between the xylem and the surrounding living tissue of the bark achieved? In order to respond to this question the water relations of the bark tissue were studied by analysing P-V curves (Table 1, Fig. 4). Similarly to what happened with $P_{\mathrm{e}}$ and $\Psi_{\mathrm{MDS}}$, Prunus showed the most extreme values with a $\Psi_{100}$ of $-2.81 \mathrm{MPa}, \Psi_{0}$ of -5.20 and $\varepsilon$ of 9.20 (MPa). However, although, once more, Olea and Citrus behaved in a similar fashion, Vitis did not present the other extreme values, and joined the two previous species. This is clearly seen in Figure 5a where Prunus is easily distinguished from the other three species. However, if $\mathrm{RWC}_{0}$ was plotted against $\Psi_{\text {stem }}$ at maximum MDS (Fig. 5b) no relationship emerged and all four species fixed their $\mathrm{RWC}_{0}$ in a narrow range between 0.60 and 0.64 . There are very scarce data about water relation parameters of this plant tissue in the literature. To the best of our knowledge, the only information available can be found in Scholz et al. (2007) in several neotropical savannah trees. These authors concluded that osmotic adjustment and values of the $\varepsilon$ of living parenchyma in the bark are critical to determine the stem capacitance and for the plant to achieve the homeostasis in the diurnal and seasonal water balance of trees. Scholz et al. (2007) interpreted the contribution of outer parenchyma to total stem capacitance as intriguing, since sapwood was found to be a major contributor to water release during high evaporative periods. However, it has to be considered that the capacity of sapwood to release water is limited by its consequence, i.e., xylem embolism. In this sense, our results show how the different species adjust their water relation parameters to optimise the water flow between tissue compartments. Parenchyma of Prunus was able to lower its osmotic potential to lower values than the other species, favouring the water exchange at $\Psi_{\text {stem }}$ down to $P_{\mathrm{e}}$. It has to be noted as well that the radial resistance between xylem and bark can vary in a diurnal and seasonal basis, affecting the water flux between these two tissues (Steppe et al., 2012). Therefore, the correlations found in this work are expected to change along the season. Indirectly, the coordination between xylem functioning and living tissues of the bark could have implications also on the coordination and regulation of stomatal conductance to avoid catastrophic embolism formation in the xylem. The decrease in water content of the living cells of the bark, among which phloem is, would affect the transport of photoassimilates from the leaves (Thompson and Holbrook, 2003), and therefore acts as a hydraulic signal influencing the photosynthesis processes, very much coordinated with stomatal conductance (Franks, 2006). The key conclusions of this work can be tested with existing model approaches, like Steppe et al. (2006) or Zweifel et al. (2007), whose performance surely will improve, especially when applied along the season.

\section{CONCLUSIONS}

Our results confirm the hypothesis that in long transport processes, as those occurring in xylem and phloem, the coordination among tissues in plant water relations parameters is very important. Since living tissue in the bark plays a key role in the plant water used, buffering diurnal fluctuations in the water demand by the canopy, we found in this study a tight correlation between the vulnerability to cavitation of xylem and the water potential at which the maximum daily shrinkage of the trunk occurs. It is demonstrated that the way that living cells in the bark adjust their osmotic pressure and bulk elastic modulus is essential to achieve this synchronization. Obviously, this has implications on the transport of photoassimilates in the phloem, and on the interactions in 
the regulation of leaf gas exchange, particularly in the stomata control of transpiration. Finally, the increase in our knowledge of the integration of the processes underneath the observed response of dendrometers or sap flow is of vital importance for understanding these responses under water stress, and to conduct a rational use of these plant-based sensors in deficit irrigation management.

\section{ACKNOWLEDGEMENTS}

This work was funded by the Spanish Ministry of Science and Innovation (research project AGL2009-11310/AGR), by the Junta de Andalucía (research project AGR-6456-2010) and by the FEDER programme. Antonio Montero helped us with the field and laboratory work. Thanks to the owners of Internacional Olivarera, S.A.U. (Interoliva), for allowing us to make the experiments in the Sanabria orchard. We also thank Silvia Seller, agronomist, and Juan Francisco Bernabé, foreman, for their technical assistance.

\section{Literature Cited}

Choat, B., Drayton, W.M., Brodersen, C., Matthews, M.A., Shackel, K.A., Wada, H. and McElrone, A.J. 2010. Measurement of vulnerability to water stress-induced cavitation in grapevine: a comparison of four techniques applied to a long-vesseled species. Plant Cell Environ. 33:1502-1512.

Cochard, H., Herbette, S., Barigah, T., Badel, E., Ennajeh, M. and Vilagrosa, A. 2010. Does sample length influence the shape of xylem embolism vulnerability curves? A test with the Cavitron spinning technique. Plant Cell Environ. 33:1543-1552.

Diaz-Espejo, A., Buckley, T.N., Sperry, J.S., Cuevas, M.V., De Cires, A., Elsayed-Farag, S., Martin-Palomo, M.J., Muriel, J.L., Perez-Martin, A., Rodriguez-Dominguez, C.M., Rubio-Casal, A.E., Torres-Ruiz, J.M. and Fernández, J.E., 2012. Steps toward an improvement in process-based models of water use by fruit trees: a case study in olive. Agric. Wat. Manag. 114:37-49.

Egea, G., González-Real, M.M., Baille, A., Nortes, P.A. and Diaz-Espejo, A. 2011. Disentangling the contributions of ontogeny and water stress to photosynthetic limitations in almond trees. Plant Cell Environ. 34:962-979.

Fernandez, J., Moreno, F., Giron, I.F. and Blazquez, O.M. 1997. Stomatal control of water use in olive tree leaves. Plant and Soil 190:179-192.

Fernandez, J.E. and Cuevas, M.V. 2010. Irrigation scheduling from stem diameter variations: a review. Agric. For. Met. 150:135-151.

Franks, P.J. 2006. Higher rates of leaf gas exchange are associated with higher leaf hydrodynamic pressure gradients. Plant Cell Environ. 29:584-592.

García-Tejero, I., Romero-Vicente, R., Jiménez-Bocanegra, J.A., Martínez-García, G., Durán-Zuazo, V.H. and Muriel-Fernández, J.L. 2010. Response of citrus trees to deficit irrigation during different phenological periods in relation to yield, fruit quality, and water productivity. Agric. Wat. Manag. 97:689-699.

Meinzer, F.C., Johnson, D.M., Lachenbruch, B., McCulloh, K.A. and Woodruff, D.R. 2009. Xylem hydraulic safety margins in woody plants: coordination of stomatal control of xylem tension with hydraulic capacitance. Funct. Ecol. 23:922-930.

Ortuño, M.F., Conejero, W., Moreno, F., Moriana, A., Intrigliolo, D.S., Biel, C., Mellisho, C.D., Pérez-Pastor, A., Domingo, R., Ruiz-Sánchez, M.C., Casadesus, J., Bonany, J. and Torrecillas, A. 2010. Could trunk diameter sensors be used in woody crops for irrigation scheduling? A review of current knowledge and future perspectives. Agric. Wat. Manag. 97:1-11.

Poggi, I., Polidori, J.J., Gandoin, J.M., Paolacci, V., Battini, M., Albertini, M., Ameglio, T. and Cochard, H. 2007. Stomatal regulation and xylem cavitation in clementine (Citrus clementina Hort.) under drought conditions. J. Hort. Sci. Biotech. 82:845-848.

Scholz, F.G., Bucci, S.J., Goldstein, G., Meinzer, F.C., Franco, A.C. and MirallesWilhelm, F. 2007. Biophysical properties and functional significance of stem water storage tissues in neotropical savanna trees. Plant Cell Environ. 30:236-248. 
Schultz, H.R. 2003. Differences in hydraulic architecture account for near-isohydric and anisohydric behaviour of two field-grown Vitis vinifera L. cultivars during drought. Plant Cell Environ. 26:1393-1405.

Steppe, K., De Pauw, D.J.W., Lemeur, R. and Vanrolleghem, P.A. 2006. A mathematical model linking tree sap flow dynamics to daily stem diameter fluctuations and radial stem growth. Tree Physiol. 26:257-273.

Steppe, K., Cochard, H., Lacointe, A. and Améglio, T. 2012. Could rapid diameter changes be facilitated by a variable hydraulic conductance? Plant Cell Environ. 35:150-157.

Thompson, M.V. and Holbrook, N.M. 2004. Scaling phloem transport: information transmission. Plant Cell Environ. 24:509-519.

Zweifel, R., Steppe, K. and Sterck, F.J. 2007. Stomatal regulation by microclimate and tree water relations: interpreting ecophysiological field data with a hydraulic plant model. J. Exp. Bot. 58:2113-2131.

\section{$\underline{\text { Tables }}$}

Table 1. Main parameters determined after analysing pressure-volume curves in the four studied species. $\Psi_{100}(\mathrm{MPa})$ is the water potential at full turgor, $\Psi_{0}(\mathrm{MPa})$ is the water potential at zero turgor, $\mathrm{RWC}_{0}$ is the tissue relative water content at zero turgor, $\varepsilon$ (MPa) is the average bulk elastic modulus of tissue.

\begin{tabular}{lcccc}
\hline & $\Psi_{100}$ & $\Psi_{0}$ & $\mathrm{RWC}_{0}$ & $\varepsilon$ \\
\hline Vitis & -1.97 & -3.36 & 0.64 & 6.93 \\
Citrus & -1.72 & -3.38 & 0.60 & 5.99 \\
Olea & -1.62 & -3.07 & 0.62 & 4.64 \\
Prunus & -2.81 & -5.20 & 0.62 & 9.20 \\
\hline
\end{tabular}

\section{Figures}

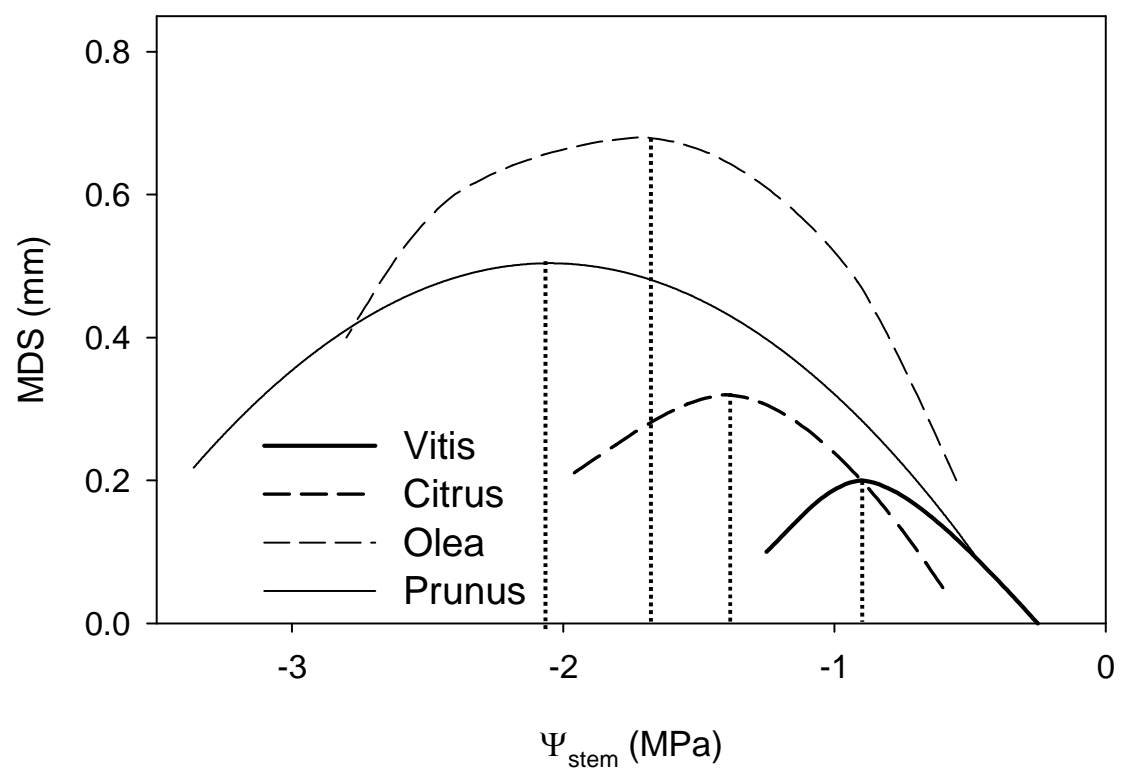

Fig. 1. Maximum daily shrinkage in the trunk (MDS) as a function of stem water potential ( $\left.\Psi_{\text {stem }}\right)$ for four different species. Dotted lines indicate the $\Psi_{\text {stem }}$ at which the MDS is reached. Vitis, Citrus and Olea data from Ortuño et al. (2010). Prunus data from this work. 


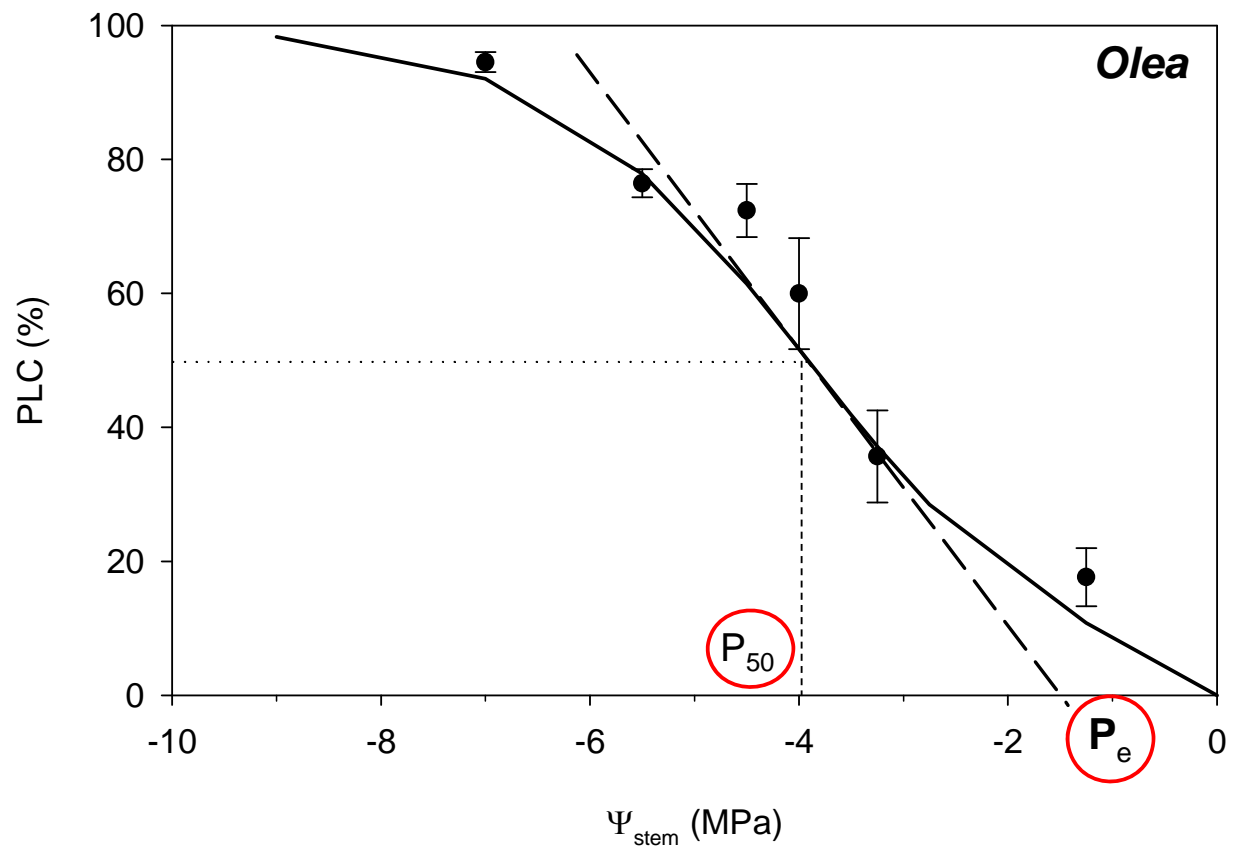

Fig. 2. Percentage of loss of hydraulic conductivity (PLC) as a function of stem water potential ( $\left.\Psi_{\text {stem }}\right)$ in Olea. $\mathrm{P}_{50}$ indicate the $\Psi_{\text {stem }}$ at which hydraulic conductivity is $50 \%$ of maximum, and $\mathrm{P}_{\mathrm{e}}$ the $\Psi_{\text {stem }}$ at which the loss of hydraulic conductivity is enhanced.

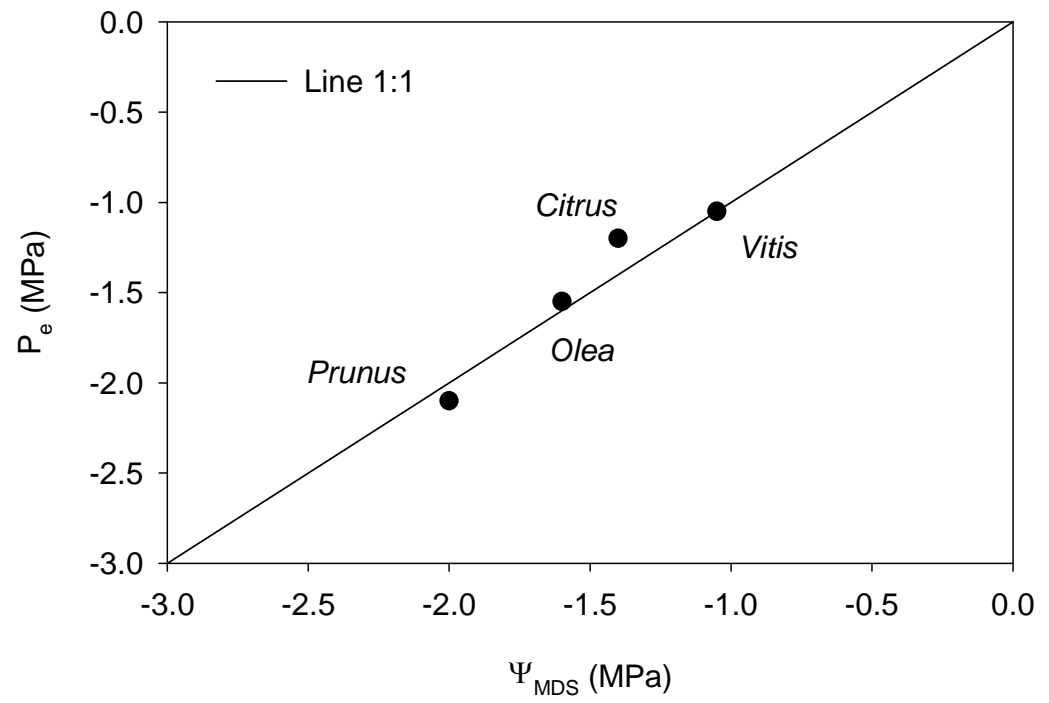

Fig. 3. Relationship between air entry stem water potential $\left(P_{\mathrm{e}}\right)$ and the $\Psi_{\text {stem }}$ at which maximum daily shrinkage is maximum ( $\Psi_{\mathrm{MDS}}$ ) for each species. 

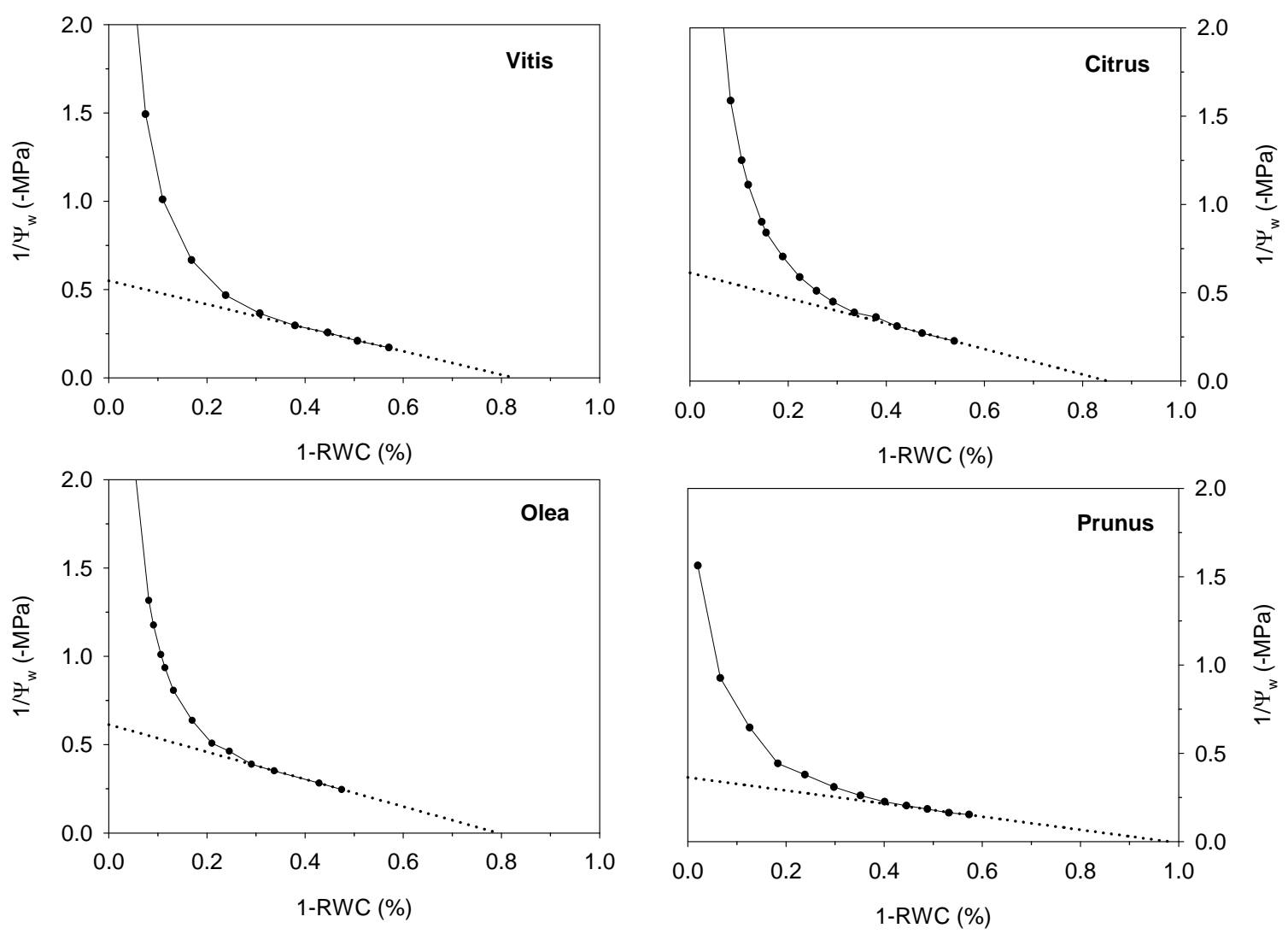

Fig. 4. Pressure-volume curves of the elastic living tissue of bark of the four studied species. Dotted line indicates the osmotic component.

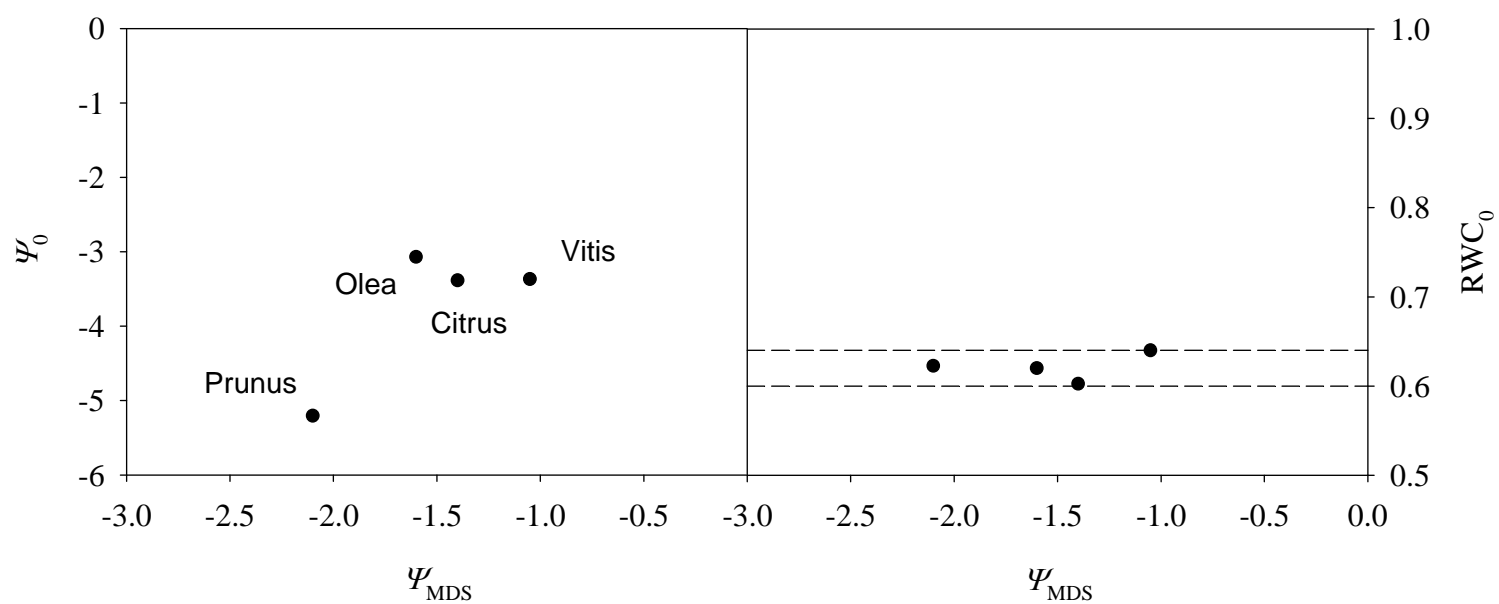

Fig. 5. Relationship between water potential of living tissue of bark at zero turgor ( $\left.\Psi_{\mathrm{o}}\right)$ and relative water content at zero turgor $\left(\mathrm{RWC}_{0}\right)$ with stem water potential $\left(\Psi_{\mathrm{s}}\right)$ at maximum trunk diameter shrinkage (MDS). Dashed lines represent the narrow range of $\mathrm{RWC}_{0}$ in all four species. 